\title{
Perspectivas para a economia mundial em 2006
}

\author{
Nilson de Paula* \\ Tácio Feres Dagostini**
}

Após a frustrante trajetória de crescimento da economia brasileira em 2005, novas expectativas são criadas para o corrente ano, nas quais, o cenário político de um ano eleitoral e o perfil da política macroeconômica terão grande influência. Os recentes eventos envolvendo mudanças no comando da política econômica poderão contaminar a evolução da atividade econômica tanto por efeitos prováveis no câmbio quanto por ajustes nos fundamentos que balizaram a trajetória da economia nos anos recentes.

Entretanto, qualquer que seja a aposta dos analistas e o grau de impermeabilidade do mercado à crise política, o cenário da economia mundial terá grande influência na trajetória da economia brasileira no ano de 2006. As previsões nesse sentido têm sido claramente conservadoras, sem indicar qualquer alento a estimular o desempenho da economia nacional num nível superior ao observado recentemente. Portanto, como será indicado na presente análise, na medida em que nada de novo parece estar reservado no front externo, o mercado interno terá um papel crucial nas projeções de crescimento do PIB. Nesse contexto, pode-se considerar que, ao contrário das previsões otimistas, a economia brasileira estaria diante de um cenário externo pouco promissor e de limitações internas criadas pela condução da política monetária de permanente cautela e de baixos níveis de investimento.

A relevância das previsões quantitativas é relativa, considerando que são freqüentemente refeitas e, não raro, se revelam errôneas com ajustes periódicos, a exemplo das previsões para a economia brasileira ao longo do ano de 2005. Após uma aposta generalizada de que a economia cresceria acima de 3,5\%, iniciando o esperado espetáculo do crescimento, o resultado foi decepcionante, ficando em 2,5\%, a menor taxa entre os países emergentes (tabela 1). Da mesma forma a taxa de crescimento da Argentina surpreendeu muitos analistas, obrigando-os a refazerem suas previsões para o ano de 2006.

Como se percebe na tabela abaixo, a economia brasileira teve o pior desempenho entre as economias emergentes, devendo manter a mesma posição no ano de 2006.

\footnotetext{
* Doutor em Economia pela University College London; Professor do Departamento de Economia da Universidade Federal do Paraná (UFPR. Endereço Eletrônico: nilson@ufpr.br

**Graduando em Ciências Econômicas pela Universidade Federal do Paraná (UFPR). Bolsista do Centro de Pesquisas Econômicas (CEPEC/UFPR). Endereço eletrônico: tac.dagos@ibest.com.br
} 
Tabela 1. Crescimento do PIB de países emergentes selecionados

\begin{tabular}{l|c|c}
\hline \multicolumn{1}{c|}{ País } & 2005 & 2006 \\
\hline China & 9,7 & 8,7 \\
Hong Kong & 7,3 & 5,1 \\
Índia & 7,7 & 7,2 \\
Indonésia & 5,1 & 4,8 \\
Singapura & 5,7 & 5,4 \\
Coréia do Sul & 4,0 & 4,7 \\
Taiwan & 3,9 & 4,1 \\
Tailândia & 4,6 & 5,1 \\
Argentina & 8,7 & 6,2 \\
Brasil & 2,5 & 3,6 \\
Chile & 6,0 & 5,4 \\
México & 3,1 & 3,5 \\
Peru & 6,1 & 4,7 \\
Venezuela & 8,4 & 5,5 \\
África do Sul & 4,9 & 4,4 \\
Rússia & 6,3 & 6,2 \\
\hline Fonsia ABN Antingn
\end{tabular}

Fonte: ABN Amro; Deutsche Bank; Economist Intelligence Unit; Goldman Sachs; HSBC; ING Financial Markets; J.P Morgan Chase; Merrill Lynch;UBS, apud The Economist, February 18th 2006, pg 98.

Por outro lado, expectativas sobre o ritmo de crescimento da economia mundial têm sido manifestadas pelos principais organismos internacionais, apesar de algumas divergências nos cenários traçados para o corrente ano. Apesar de diferentes interpretações e ponderações dos fenômenos que afetam as principais economias e seus desdobramentos para as tendências globais, há um relativo consenso de que a economia mundial deverá no máximo manter o mesmo ritmo do ano anterior. Segundo o FMI a economia mundial deverá crescer mais do que os 4,3\% previstos em setembro de 2005, após a Zona do Euro ter dado sinais de forte crescimento em janeiro de 2006, levando o Fundo a rever para cima suas apostas. Enquanto a UNCTAD e o Banco Mundial prevêem um crescimento de 3\% e 3,2\%, respectivamente. Mesmo assim há uma coincidência nas previsões desses organismos de que a estabilidade global deverá ser uma resultante de uma desaceleração das economias avançadas. "Apesar dessas projeções de estabilidade relativa, nenhuma das instituições descarta a possibilidade de a situação complicar-se”. (Valor Econômico, 2005) 
Tabela 2. Perspectivas para o crescimento econômico mundial em 2006

\begin{tabular}{l|c|c|c}
\hline País & FMI & ONU & Banco Mundial \\
\hline EUA & 3,3 & 3,1 & 3,5 \\
Zona do Euro & 1,8 & 2,1 & 1,4 \\
Japão & 2,0 & 2,0 & 1,8 \\
Economia Mundial & $\mathbf{4 , 3}$ & $\mathbf{3 , 0}$ & $\mathbf{3 , 2}$ \\
\hline
\end{tabular}

Fonte: FMI, ONU, Banco Mundial

Essa previsão está evidentemente condicionada à evolução das principais economias, cujos ritmos de crescimento deverão estar abaixo da média dos países emergentes. Tendo por base estimativas do FMI, a economia americana deverá crescer 3,3\%, influenciada pela necessidade de administrar os persistentes déficits comercial e fiscal, associada a uma estratégia do Federal Reserve de elevação da taxa de juros para 5\% ao longo do ano. Ou seja, sua capacidade de sustentar boa parte do crescimento mundial pode enfraquecer, considerando que seu déficit em conta corrente chegou a 6,5\% do PIB no final de 2005, devendo aumentar para 6,7\% em 2006 e 7\% em 2007 (OECD) enquanto o déficit comercial bateu novo recorde, crescendo um quinto em relação a 2004. (The Economist, pg 96, February 18th 2006.), apesar da desvalorização do Dólar. Portanto, uma correção de rumos adotada pelo Fed, visando compensar os efeitos negativos do boom imobiliário, o baixo nível de poupança das famílias e a difícil diplomacia cambial com a China, pode resultar em dificuldades para o restante da economia mundial, em particular os países emergentes.

Os problemas gerados pelos furacões, a crise energética associada à ainda preocupante situação do petróleo e o contínuo aperto monetário por parte do Federal Reserve culminaram em uma variação de 2,7\% na produção industrial frente aos 4,4\% observado no ano de 2004 . Para a OCDE este quadro conjuntural da economia americana tende a permanecer, com uma maior aceleração nos preços do petróleo, podendo gerar um aumento da inflação para os próximos meses.

As estimativas para a Zona do Euro são das mais variadas, apesar da sensatez das políticas econômicas adotadas pelo Banco Central Europeu, mantendo os juros baixos para estimular os investimentos e derrubando a cotação da moeda frente ao dólar de $€ 0,75 \mathrm{em}$ janeiro de 2005, para $€ 0,83$ em fevereiro de 2006, contribuindo, portanto para as complicações do déficit comercial americano. Tais medidas trouxeram um importante resultado, fazendo com que a economia da Zona do Euro obtivesse uma variação positiva de $1,3 \%$ em 2005 frente aos resultados de $0,8 \%$ e $0,5 \%$ em 2002 e 2003. 
Para o Japão são esperados um aquecimento da economia com forte suporte na economia doméstica e uma menor dependência das exportações para o crescimento, isto se deve ao alto investimento das empresas privadas nos setores de pesquisa e desenvolvimento $(\mathrm{P} \& \mathrm{D})$, o qual requerem alto grau de tecnologia e alto valor agregado compensando a queda das exportações para a China.

A economia chinesa, segundo as Nações Unidas, irá seguir seu ritmo de crescimento, embora menor em 2006, 8,3\% impulsionados pelo crescente nível de exportações e queda nas importações. Menção deve ser feita às estimativas da OCDE que prevêem um crescimento maior em 2006, de 9,4\% contra 9,3\% em 2005. Entretanto, parece que a política monetária chinesa seguirá na direção oposta à seguida pelo Fed, na medida em que a demanda doméstica deve ter um papel mais importante e a política fiscal mais leniente. Apesar disso, a OCDE estima uma redução da inflação relativamente ao ano anterior.

Por outro lado, a economia chinesa estará ainda diante do dilema cambial, definido pela crescente pressão americana para ampliar a margem de valorização, associada ao influxo de capital e saldos favoráveis na balança de pagamentos. A necessidade da valorização do Yuan, esbarra na lógica da política cambial de aumentar superávits externos. Apesar do elevado saldo da balança comercial chinesa espera-se um contínuo superávit nas transações comerciais com outros países. Deve ser lembrado todavia, que a valorização do Yuan de 2,1\% frente ao Dólar em meados de 2005, foi acompanhada por uma valorização de 0,3\% em relação à demais moedas.

Por fim, segundo o último relatório do Banco Mundial, o crescimento econômico para o conjunto da América Latina e Caribe é estimado em 3,9\%, devido aos preços das commodities, principais produtos da pauta de exportação, com destaque para o petróleo, café e cobre, representando $65 \%$ do total de commodities exportadas da região.

Com base no panorama e nas previsões para o ano de 2006, em especial as relacionadas às economias avançadas, pode-se afirmar que os países emergentes terão um importante papel no crescimento da economia mundial. Mas, especificamente, as perspectivas da economia brasileira estão fortemente condicionadas às condições externas tendo em vista os sucessivos superávits da balança comercial no período recente. Nesse sentido, mesmo que a maior parcela das exportações ainda se destinem à Europa e Estados Unidos, atenção deve estar voltada também para a dinâmica de recuperação e crescimento das economias emergentes. 


\section{Referências Bibliográficas}

COTIS, J. P. (2005). How robust is the recovery?, OECD Observer no. 252/253, Nov. COSTA, C. (2006). Águas ainda tranqüilas, Revista da Indústria Brasileira, fevereiro 2006 OECD (2005), Economic Policy Reforms, Going for Growth 2006. Disponível em: http://www.oecd.org/economics

GAZETA MERCANTIL (2005). FMI tendência de queda do PIB global, 22 de setembro.

Secretaria de Comércio Exterior (SECEX). Acompanhamento Internacional, Disponível em: http://www.desenvolvimento.gov.br

THE ECONOMIST (2006). Emerging-market indicators, February $18^{\text {th }}-24^{\text {th }}$. UNITED NATIONS (2005). World Economic Prospects 2006. Disponível em: http//www.un.org

VALOR ECONÔMICO (2006). Japão reverte tendência de fuga das empresas, 21 de março.

VALOR ECONOMICO (2006). FMI revê crescimento global para cima, 16 de março.

WORLD BANK (2005), Global Economic Prospects - Economic Implications of Remittances and Migration 2006. Disponível em: http://www.worldbank.org 
